\title{
Assessment of Self Medication Practices Among Community People
}

\author{
Dr. Kandavalli Sridevi ${ }^{1 *}$, M. Venkata Subbaiah ${ }^{2}$, M. Surekha ${ }^{2}$, J.Harini $^{3}$ \\ D. Sujana ${ }^{3}$, A. Ravi Sankar \\ ${ }^{I}$ Associate Professor I/C HOD, Department of Pharmacology, Rajiv Gandhi Institute of Medical Sciences, \\ Kadapa, Andhra Pradesh, India -516003 \\ ${ }^{2}$ Assistant professor, P. Rami Reddy Memorial College of Pharmacy, Kadapa, Andhra Pradesh, India-516003 \\ ${ }^{3}$ Doctor of pharmacy, P. Rami Reddy Memorial College of Pharmacy, Kadapa, Andhra Pradesh, India-516003 \\ ${ }^{1}$ *Corresponding author Dr.Kandavalli Sridevi. MD email: drsridevi19@gmail.com Mobile: 7386226669.
}

\begin{abstract}
In India, self-medication is an obvious choice with the risk of adverse drug reactions, drug resistance, disease hidden progress, and with raising morbidity or mortality as health care is relatively expensive and availability of prescription drugs as an OTC medication. We aimed to assess the practice of self medication, educate and curtail self-medication. A community-based survey was conducted among the age group of 16 - 60 year people who visits community pharmacies and students in Rajiv Gandhi institute of medical sciences, by using a well structured questionnaire the data was collected and analyzed to determine the practice. A total of $42.10 \%$ had taken self-medication for body pains and fever, 36.40\% for headache, $27.19 \%$ for Cold, 21.05\% for Cough. Oral tablet was frequently used (90.35\%) dosage form. In class of medications, $77.63 \%$ were NSAIDs. We observed that $23.24 \%$ of the patients were come to the pharmacies to refill their old prescriptions without physician authentication for their own and neighbors. Almost $35 \%$ were practiced selfmedication for 1-5 years. We conclude that a stringent regulatory authority monitoring is essential to minimize and prevent the practice and hazards of self-medication. And also periodical awareness campaigns in community will reduce this practice.
\end{abstract}

Key words: Self-medication, Community-based, Questionnaire.

\section{Introduction}

Every day, we are practicing self-medication in the form of self-care of our health. Self-medication has traditionally been defined as "the taking of drugs, herbs or home remedies on one's own initiative, or on the advice of another person, without consulting a doctor."

Families, friends, neighbors, the pharmacist, previous prescribed drug, or suggestions from an advertisement in newspapers or popular magazines are common sources of self medications. Although responsible self-medication have their own benefits such as reduce the cost of treatment, travelling time as well as doctor's time i.e., consultation time, they also bring with serious disadvantages such as wastage of resources, increased resistance of pathogens and causes serious health hazards such as adverse reaction overdose, drug interactions, misdiagnosis and prolonged suffering[1].

In developing countries drug monitoring system is very poor and it is very easy to buy any drug with or without Prescription [2]. Antimicrobial resistance is a current problem worldwide particularly in developing countries where antibiotics are available without any prescription. In India, it is very common to see selfmedication practice and which is emerging challenge to health care provider [1].

1.1 List of commonly used drugs for self-medication [3].

\begin{tabular}{|l|l|}
\hline Category & Drug \\
\hline Cough/cold & $\begin{array}{l}\text { Aminophylline, Camphor, Chlorphenaramine maleate, codeine phosphate, Dextromethorphan, Ephedrine } \\
\text { Hcl, Eucalyptus oil, Menthol, Xylometazoline Hcl. }\end{array}$ \\
\hline Analgesic & Acetaminophen, Ibuprofen, Aspirin, Camphor. \\
\hline Antacid & Aluminium hydroxide, magnesium carbonate, Magnesium hydroxide. \\
\hline Anti-fungal & Clotrimazole. \\
\hline Anti-microbial & Povidone iodine, Thimerosal. \\
\hline Vitamin supplements & Vitamin A, Vitamin E, Vitamin B complex. \\
\hline
\end{tabular}

\subsection{Prevalence}

The prevalence rates are high all over the world; up to $68 \%$ in European countries and 57\% in USA, while much higher in the developing countries with rates going as high as $92 \%$ in the adolescents of Kuwait. The prevalence rates of self medication and self care are 31\% in India, 59\% in Nepal and 51\% in Pakistan [4]. 
In India self-medication is very common among educated population. In Punjab, the prevalence of selfmedication was 73\% [1]. In India, the prevalence of Self medication among pre-school age children has been reported to be 58.91\% [5]. In one Spanish study by Dr.Pilar Carrasco 1 in 5 people engage in self-medication, using an over-the-counter drug, alcohol, street drugs, or drugs prescribed for a different purpose, to alleviate an illness or condition, without professional supervision[6]. Perception of illness and incessant advertising, among others, have increased the prevalence of self-medication which accounts for about $2.9-3.7 \%$ causes of death in hospitals as a result of drug-drug interactions [7]. Self-medication use is highly prevalent in Germany, particularly among children and adolescents from families with a higher socioeconomic status [8].

\subsection{Reasons Of Self Medication}

A number of reasons could be enumerated for self-medication like

- Urge of self care

- Lack of time

- Lack of health services

- Financial constraints

- Ignorance

- Feeling of sympathy toward family members in sickness

- Misbelieves

- Extensive advertisement

- Availability of drugs in other than drug shops [1].

1.4 Risks Associated With Self Medication[9]

- Incorrect self-diagnosis.

- Delays in seeking medical advice when needed.

- Infrequent but severe adverse reactions.

- Dangerous drug interactions.

- Incorrect manner of administration.

- Incorrect dosage.

- Incorrect choice of therapy.

- Masking of a severe disease.

- Risk of dependence and abuse.

- Use of excessive drug dosage.

- Prolonged duration of use

\subsection{The Following OTC Medicines Advertising Can Be Seen on TV in India}

Digestives, antacids, antiflatulents, cold rubs and analgesic balms/creams, vitamins/tonics/health supplements (especially herbals and Ayurvedic-registered), medicated skin treatment, analgesic/cold tablets, antiseptic creams/liquids, glucose powders, cough liquids, throat lozenges, medicated dressings (band-aids), baby gripe water, Ayurvedic medicines and preparations[10]. Self medication increases the risk of adverse drug reactions, drug resistance, and masks the diseases along with economic burden on patients. Main problem with self medication in developed countries is antibiotic resistance. Potential risks of self-medication practices include: incorrect self-diagnosis, delays in seeking medical advice when needed, infrequent but severe adverse reactions, dangerous drug interactions, incorrect manner of administration, incorrect dosage, incorrect choice of therapy, masking of a severe disease and risk of dependence and abuse.

Self medication may increase morbidity or mortality of people.

We aimed to estimate the rate of self medication among the urban population in Kadapa and to provide awareness on hazards of self medication and to educate the community regarding the implications of self medication with following objectives.

$>$ To describe self-medication practices among general population

$>$ To identify potential factors those are associated with self-medication practices.

$>$ To identify reasons for self-medication practices.

$>$ To provide awareness and education regarding the implications of self medication.

$>$ To know Categories of medications which are most preferred?

$>$ To know Preferred dosage form during self medication.

$>$ To know awareness on drug/food interactions.

$>$ To provide information about hazards of self medication. 


\subsection{Study Details}

\section{Research Methodology}

\section{Place of study:}

The study "Assessment of self medication practices among dispensing pharmacists and community", which was carried out in the Rajiv Gandhi Institute of Medical Sciences (RIMS) and community Pharmacies in Kadapa.

Study duration $\quad$ : Data collection period was 6 months (from April to September, 2013)

Study design : Community based survey

Study population $\quad$ : General population and Students

The study was approved by the Institutional Ethics and Research Committee of Rajiv Gandhi Institute of Medical Sciences, Kadapa.

\subsection{Study Eligibility}

Subjects were enrolled in the study based on Inclusion and Exclusion Criteria

2.2.1 Inclusion criteria : Subjects with non-doctor prescription in age group between $16-60$ years.

2.2.2 Exclusion criteria : Subjects with doctor prescription

\subsection{Study Materials}

\subsubsection{Informed consent form}

2.3.2 A well structured Patient data collection and Questionnaire form

2.3.3 A well structured patient education leaflets on self medication hazards

\subsection{Method of Study}

- In this study 16 pharmacies were selected randomly from Kadapa city, and students of Rajiv Gandhi Institute of Medical Sciences in Kadapa.

- Subjects who were attended pharmacies without prescription, students in RIMS were selected.

- The objectives of the study were explained to the study participants prior to data collection, and their consents were sought, and the questionnaires were filled only by those who agreed.

- The respondents were classified as urban. Information regarding self-medication, the type of medication, illness for which the medication was used and reason for not consulting a doctor along with the sources of information about the drug were collected by using questionnaire form.

- During the 6 months period we collected information by using questionnaire form. After collecting information the subjects were educated regarding self medication and its hazards by providing leaflets on self medication.

- The study consisted of a survey of the use of self medication to ascertain

1. Socio-economic factors and education level that influences self medication

2. Conditions treated by self medication

3. Categories of medications preferred

4. Preferred dosage form during self medication

5. Reasons for self medication

6. Influence of chronic illness

7. Awareness of drug/food interactions

8. Source on self medication

- Data analysis was determined as percentage of the total sample. The results were presented in absolute figures (percentages) as depicted in Tables, Figures and Charts.

\section{Results}

A total of 228 of subjects were recruited in this study per inclusion criteria.

\subsection{Demographics}

3.1.1 TABLE 1 explains the demographics of the study subjects. Among 228 individuals $50.87 \%$ (116) males and $49.12 \%$ (112) females were included in this study. Among 228 individuals, $47.36 \%$ (108) subjects were between age group of $16-25$ years, $32.45 \%$ (74) subjects were between age group of $26-35$ years, $10.08 \%$ (23) subjects were between age group of 36-45 years, $7.89 \%$ (18) subjects were between age group of 46-55 years, $2.19 \%$ (5) subjects were between age group of $>55$ years. The age group between 16-25 years were used more self medication than others.

Out of 228 subjects, $89.03 \%$ (203) subjects were literate, $10.96 \%$ (25) subjects were illiterate, $39.91 \%$ (91) subjects were students, $24.12 \%$ (55) subjects were employs, $13.15 \%$ (30) subjects were coolly, $12.71 \%$ (29) subjects were doing business, and $10.52 \%$ (24) subjects were house wives. 
TABLE 1: Demographics of the Study Subjects

\begin{tabular}{|l|l|l|}
\hline Gender & Number of patients n=228 & Percentage \\
\hline Male & 116 & $50.87 \%$ \\
\hline Female & 112 & $49.12 \%$ \\
\hline Age & \multicolumn{2}{|l|}{} \\
\hline $16-25$ & 108 & $47.36 \%$ \\
\hline $26-35$ & 74 & $32.45 \%$ \\
\hline $36-45$ & 23 & $10.08 \%$ \\
\hline $46-55$ & 18 & $07.89 \%$ \\
\hline$>55$ years & 05 & $02.19 \%$ \\
\hline Educational status & \multicolumn{2}{|l|}{} \\
\hline Literate & 203 & $89.03 \%$ \\
\hline Illiterate & 25 & $10.96 \%$ \\
\hline Occupation & \multicolumn{2}{|l|}{$39.91 \%$} \\
\hline Student & 91 & $24.12 \%$ \\
\hline Employ & 55 & $13.15 \%$ \\
\hline Coolly & 30 & $12.71 \%$ \\
\hline Business & 29 & $10.52 \%$ \\
\hline House wife & 24 & \\
\hline
\end{tabular}

\subsection{Number of times fallen ill}

TABLE 2 explains about the distribution of subjects based on number of times fallen ill for self medication. Out of 228 subjects, $3.94 \%$ (9) subjects were fallen ill for 1 time, $10.08 \%$ (23) subjects were fallen ill for 2 times, $21.92 \%$ (50) subjects were fallen ill for 3 times, $62.28 \%$ (146) subjects were fallen ill for above 3 times.

TABLE 2: Distribution of Subjects Based on Number of Times Fallen Ill

\begin{tabular}{|l|l|l|}
\hline Number of Times Fallen IIl & Number of Subjects $(\mathbf{n}=\mathbf{2 2 8})$ & Percentage $(\%)$ \\
\hline 1 time & 9 & 03.94 \\
\hline 2 times & 23 & 10.08 \\
\hline 3 times & 50 & 21.92 \\
\hline$>3$ times & 146 & 62.28 \\
\hline
\end{tabular}

\subsection{Medical conditions (signs/symptoms)}

Out of 228 subjects, $42.10 \%$ (96) subjects had complains of Body pains, $42.10 \%$ (96) subjects had complains of Fever, $36.40 \%$ (83) subjects had complains of Head ache, 27.19\% (62) subjects had complains of Cold, $21.05 \%$ (48) subjects had complains of Cough, 10.96\% (25) subjects had complains of Stomach ache $10.52 \%$ (24) subjects had complains of Gastritis, $10.52 \%$ (24) subjects had complains of vomiting, 9.21\% (21) subjects had complains of Breathlessness, 7.45\% (17) subjects had complains of Hypertension, 6.57\% (15) subjects had complains of Diarrhea, 5.26\% (12) subjects had complains of Throat pain, 4.38\% (10) subjects had complains of Diabetes mellitus, 3.94\% (9) subjects had complains of skin rashes, 3.94\% (9) subjects had complains of Allegis, 3.07\% (7) subjects had complains of Eye/Ear infection, 3.07\% (7) subjects had complains of Giddiness, $2.19 \%$ (5) subjects had complains of Constipation, 2.19\% (5) subjects had complains of Tooth ache, $1.75 \%$ (4) subjects had complains of Acne, $1.75 \%$ (4) subjects had complains of Fatigue, 1.37\% (3) subjects had complains of Chest pain which was shown in the "Fig 1".

Note: Some questions had multiple options respondents could select and hence the sum of the percentages is not always $100 \%$.

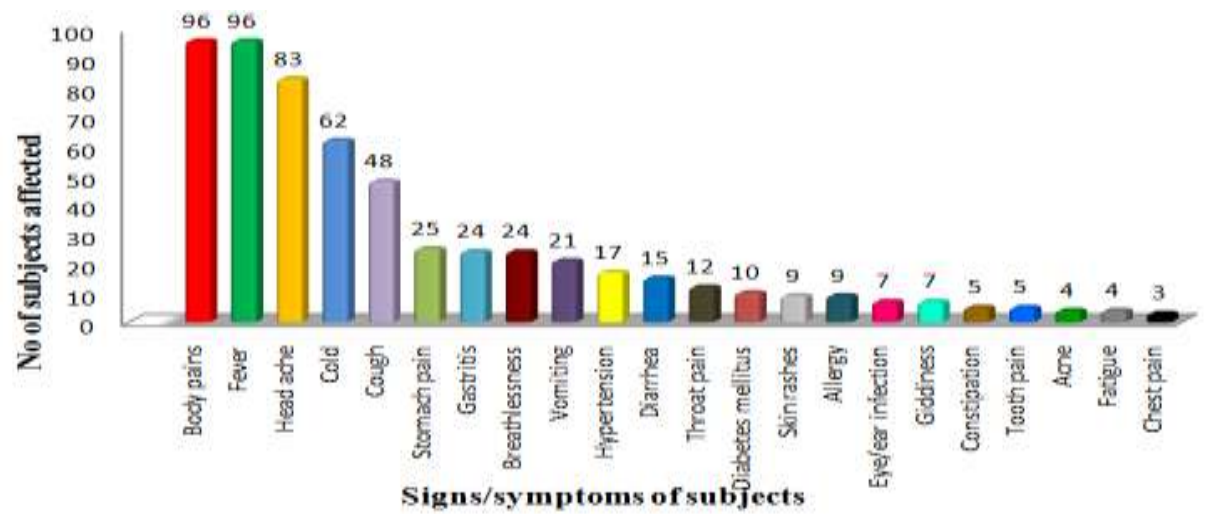

FIGURE 1: Medical conditions for which Self Medication Utilized

3.4 Type Of Dosage Form Used 
Among 228 recruited subjects, 90.35\% (206) subjects had used tablets, 25\% (57) subjects had used capsules, $14.03 \%$ (32) subjects had used syrups, 9.21\% (21) subjects had used ointments, $7.45 \%$ (17) subjects had used other dosage forms like drops, and mouth washes etc shown in TABLE 3.

TABLE 3: Type of Dosage Form Used.

\begin{tabular}{|l|l|l|}
\hline Dosage Form & Number of Subjects $(\mathbf{n = 2 2 8})$ & Percentage $(\%)$ \\
\hline Tablets & 206 & 90.35 \\
\hline Capsules & 57 & 25 \\
\hline Syrups & 32 & 14.03 \\
\hline Ointments & 21 & 9.21 \\
\hline Others & 17 & 7.45 \\
\hline
\end{tabular}

NOTE: Some questions had multiple options respondents could select and hence the sum of the percentages is not always $100 \%$

\subsection{Category Of Drugs Used In Self Medication}

TABLE 4 explains about the subject's distribution based on category of drugs used in self medication. Out of 228 subjects, 77.63\% (177) subjects had used NSAID'S, 32.89\% (75) subjects had used Antibiotics, $28.07 \%$ (64) subjects had used Antihistamines, $21.92 \%$ (50) subjects had used Anti ulcer, 15.35\% (35) subjects had used Anti-tussives, 11.84\% (27) subjects had used Antispasmodic, 9.21\% (21) subjects had used Anti emetics, $8.77 \%$ (20) subjects had used Vitamins supplements, $8.33 \%$ (16) subjects had used Anti hypertensive, $5.26 \%$ (12) subjects had used Bronchodilators, $4.38 \%$ (10) subjects had used Anti diabetic, 3.94\% (9) subjects had used Anti amoebic, 3.94\% (9) subjects had used Expectorants, 3.07\% (7) subjects had used Corticosteroids, $2.19 \%$ (5) subjects had used Laxatives, $1.31 \%$ (3) subjects had used Cardiac drugs, $0.87 \%$ (2) subjects had used Anti-protozoal, $0.43 \%$ (1) subject had used Anti migraines, $0.43 \%$ (1) subject had used Mouth washes

TABLE 4: Category of Drugs

\begin{tabular}{|l|l|l|}
\hline Category of Drugs & No of Subjects Taken $(\mathbf{n}=228)$ & Percentage (\%) \\
\hline NSAID'S & 177 & 77.63 \\
\hline Antibiotics & 75 & 32.89 \\
\hline Anti histamine & 64 & 28.07 \\
\hline Anti ulcerative & 50 & 21.92 \\
\hline Antitussive & 35 & 15.35 \\
\hline Antispasmodic & 27 & 11.84 \\
\hline Antiemetic & 21 & 09.24 \\
\hline Vitamin supplement & 20 & 08.77 \\
\hline Antihypertensive & 16 & 08.33 \\
\hline Bronchodilator & 12 & 05.26 \\
\hline Antidiabetic & 10 & 04.38 \\
\hline Anti amoebic & 09 & 03.94 \\
\hline Expectorants & 09 & 03.94 \\
\hline Corticosteroids & 07 & 03.07 \\
\hline Laxatives & 05 & 02.19 \\
\hline Cardiac drugs & 03 & 01.31 \\
\hline Anti protozoal & 02 & 0.87 \\
\hline Anti migraine & 01 & 0.43 \\
\hline
\end{tabular}

\subsection{Reasons For Self Medication}

Subjects were distributed based on the reasons for self medication. Among the 228 recruited subjects, $62.71 \%$ (143) subjects had used the reason of quick relief, 55.70\% (127) subjects had used the reason of availability of drugs, $37.71 \%$ (86) subjects had used the reason of minor ailments, $25.43 \%$ (58) subjects had used the reason of previous prescription, $15.78 \%$ (36) subjects had used the reason of high consultation fee, $11.40 \%$ (26) subjects had used the reason of lack of time, $10.52 \%$ (24) subjects had used the reason of Illiteracy as shown in the TABLE 5 .

TABLE 5: Reasons for self medication

\begin{tabular}{|l|l|l|}
\hline Reasons For Self Medication & Number Of Subjects $(\mathbf{n = 2 2 8})$ & Percentage $(\%)$ \\
\hline Quick relief & 143 & 62.71 \\
\hline Availability of drugs & 127 & 55.70 \\
\hline Minor ailments & 86 & 37.71 \\
\hline High consultation fee & 58 & 25.43 \\
\hline Previous prescription & 36 & 15.78 \\
\hline Lack of time & 26 & 11.40 \\
\hline Illiteracy & 24 & 10.52 \\
\hline DOI: $10.9790 / 0853-1605017582$ & www iosrjournals.org \\
\hline
\end{tabular}




\subsection{Subject Distribution Based On Personal Habits}

Out of 228 subjects, $14.91 \%$ (34) subjects had the habit of Alcohol, $14.91 \%$ (34) subjects had the habit of Smoking and $70.17 \%$ (160) subjects had not any of the above habits as shown in the "Fig 2".

\section{NUMBER OF SUBJECTS $(\mathrm{n}=\mathbf{2 2 8})$}

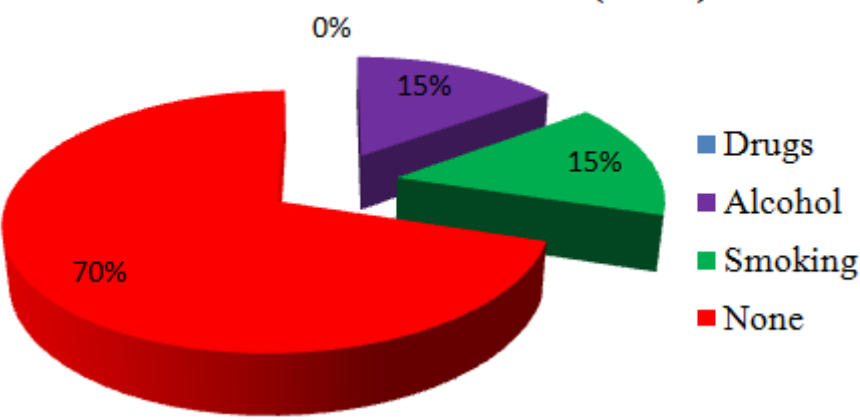

Figure 2: Distribution of Subjects Based on Personal Habits

\subsection{Subject Distribution Based On Presence Of Chronic Illness}

Out of 228 subjects, 8.33\% (19) subjects were suffering from chronic illness (Hyper tension-11, Diabetes mellitus-6, Liver cirrhosis-2), 79.38\% (181) subjects were not suffering from any chronic illness.

\subsection{Awareness Of Drug Interactions}

Subjects were distributed based on personal habits. Out of 228 subjects, $21.92 \%$ (50) subjects having awareness of drug interactions, 78.07 (178) subjects were not having awareness of drug interactions.

\subsection{Source Of Information}

Out of 228 subjects, $7.7 \%$ (80) subjects took information from pharmacist, $24.12 \%$ (55) subjects self medication by themselves, $23.24 \%$ (53) subjects took information from previous prescription, $7.7 \%$ (34) subjects took information from Advertisement, 7.7\% (32) subjects took information from Friends and $7.7 \%$ (27) subjects took information from Nurse as shown in the "Fig 3 ".
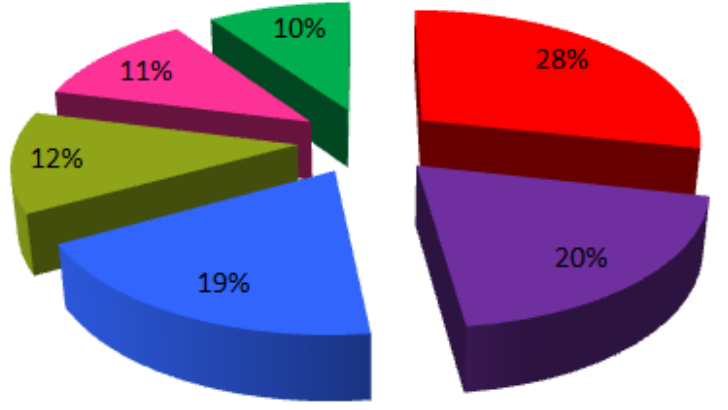

$$
\begin{aligned}
& \text { - Pharmacist } \\
& \text { - Self } \\
& \text { - Previous prescription } \\
& \text { m Advertisement } \\
& \text { - Friend } \\
& \text { nurse }
\end{aligned}
$$

Figure 3: Distribution of subjects based on source of information

\subsection{Subject Distribution Based On History Of Self Medication Practice}

TABLE 6 explains the distribution of subjects based on the history of self medication habit. Out of 228 subjects, $14.03 \%$ (32) subjects had used self medication between $0-1$ year, $34.64 \%$ (79) subjects had used self medication between $1-2$ years, $34.64 \%$ (79) subjects had used self medication between $2-5$ years, $12.28 \%$ (28) subjects had used self medication between 5-10 years, $4.38 \%$ (10) subjects had used self medication >10 years.

TABLE 6: Distribution of Subjects based on history of self medication practice.

\begin{tabular}{|l|l|l|}
\hline Number of Years & Number of Subjects $(\mathbf{n}=\mathbf{2 2 8})$ & Percentage $\mathbf{( \% )}$ \\
\hline $0-1$ year & 32 & 14.03 \\
\hline $1-2$ years & 79 & 34.64 \\
\hline $2-5$ years & 79 & 34.64 \\
\hline $5-10$ years & 28 & 12.28 \\
\hline$>10$ years & 10 & 04.38 \\
\hline
\end{tabular}




\section{Discussion}

The operational definition for this study is defined as "obtaining and consuming drugs without the advice of physician either for diagnosis, prescription surveillance of treatment".

We acknowledge that this type of study using a self administered questionnaire is largely dependent upon information given by respondents. Current study revealed that self-medication was a common practice among different age groups, gender, financial situations, and education levels.

Analysis of data showed that the self medication practice was similar in male $(50.87 \%)$ and in female $(49.12 \%)$.

Males are free more to go outside, they are economically strong and have more access to medical stores. Reason for slight decrease of self medication among female may be due to less independence to women in our society, more dependency over males in every matter. This was opposed by Luca Garofalo et al, study conducted in Italy. [11]

Self medication was most common in the age group of 16-25 years $(47.36 \%)$ followed by $26-35$ years $(32.45 \%)$, and was least in the age group of $>55$ years $(2.19 \%)$. An increase pattern of self medication practices were found in the younger age group. This may be due to fact that younger people becoming more aware of their health needs and to save time and money. This was supported by Shahbaz Baig study conducted in Faisalabad [12].

This study showed that $89.03 \%$ of educated people and $10.96 \%$ of uneducated people practiced self medication. This was supported by N.A. El-Nimr et al, study conducted in Alexandria, Egypt [13]. Probably this educated group has more ability to self medicate. Education appear to be an important variable as the higher the purchaser's education level, the more the complied with reading patient information leaflet, label instructions and expiry date.

The distribution of self medication practices amongst various occupations were also analyzed and found that there were more tendency of self medication among students which was $39.91 \%$ and least in house wife $10.52 \%$ which was opposed by M.G. Sangeetha Nair et al study conducted in Thiruvananthapuram district[14], which was supported by a study conducted in Spain that the occupation also affects the practices of self medication and showed that in house wife $31.5 \%$ and in student it was $53.9 \%$ prevalence of selfmedication.

The practice of self illness was $62.28 \%$ in those having history of more than 3 times of illness as compared to $3.94 \%$ in 1 time ill history subjects. It indicates that self medication practices increased with the increase in illness.

The most common symptoms responsible for self-medication were related to body pains and fever, followed by headache, cold, and cough with the respective episode prevalence of 96 (42.10\%), $83(36.40 \%), 62$ $(27.19 \%)$, and $48(21.05 \%)$. This was supported by Girma Belachew Gutema et al study conducted in Ethiopia [15] Others like stomach pain, gastritis, breathlessness, vomiting etc were also reported though few.

Current study showed that the commonly used dosage forms were tablets $(90.35 \%)$ followed by capsules $(25 \%)$ and the least included other (7.45\%). One study in University of Jos, Jos, Nigeria by A Auta et al, also reported similar findings [16]. The participants mostly preferred tablet dosage forms as they were easy to manage compared to other dosage forms

The most common classes of drugs used in self medication in the current study were NSAIDs (antipyretics/analgesics), which was reported by $177(77.63 \%)$ of the respondents followed by antibiotics 75 $(32.89 \%)$. Other common types of medications reported were antihistamines 64 (28.07\%), antiulceratives 50 $(21.92 \%)$ and antitussives $35(15.35 \%)$ and the least was antimigraine $1(0.43 \%)$. One study in Mozambique by Lucas R et al 2010, also reported similar findings [17]. Analgesics (non-narcotics) especially NSAIDs were the most common class of medications used in the self-medication practices as reported in many studies in other areas. This is because such drugs are used to treat simple common illness, example, body pains, fever and headache. Self-medication with antibiotics can lead to the emergence of the dangerous worldwide problem of antibiotics resistant micro-organisms. Cost and toxicity can also be indicated as problems associated with the use of antibiotics in self-medication. Moreover, Arzi A et al, (2010), argue that people may abuse antibiotics by using them for such wrong indications as common cold or infections of non-bacterial origin [18].

It has been observed that among the major reasons for self- medication were mainly for quick relief $62.71 \%$, availability of drugs $55.70 \%$, and minor ailments accounts for $37.71 \%$ etc. It showed that most of the respondents were not interested to consult the physician for simple common illness (body pains and fever) and to save money and time. This was supported by Dr. Shumaila Humayun et al study conducted in Rawalpindi [19].

The main source of medications for those self-medicated was pharmacist in drug retail outlets $35.08 \%$, followed by self medicates $24.12 \%$, and the least was nurse $11.84 \%$ and was supported by G Mariam A and Worku S study [20]. The availability of drugs in informal sectors such as open markets and kiosks (small shops) encourage the rampant practice of self-medication. In order to decrease unnecessary health risk and bacterial 
resistance due to improperly obtained and used drugs, it is important to consider the manners of drug availability to consumers.

\section{Conclusion}

The assessment of self-medication is one important element in the study of rational drug use. Thus, drug regulatory and health authorities have to dedicate some resources used to raise awareness of the general public and students on the pros and cons of responsible self-medications to eventually improve their attitudes towards the practices of self-medication. Moreover, it might be helpful if the concepts and principles of selfmedication could be reflected in the formal curricula of health care disciplines in India.

Self medication should be considered as a serious problem, especially among young population and measures to reduce it or improve it, by better drug information and provision of adequate health facilities should be considered.

Among all the reasons for self medication the vital one is dispensing of medicines without registered medical practitioner's order/prescription, dispensing medicine against unauthorized, incomplete prescriptions and not fallowing the dispensing guidelines.

There is an urgent need for addressing this issue and streamlining of drug dispensing guidelines in order to control the dispensing of medicines without prescription. Clinical pharmacist should play a key role in educating dispensing pharmacist about the dispensing policies and patients about self medication and its adverse consequences.

The findings of this research should form the basis for future interventional plans to maximize benefits and minimize risks.

\section{Acknowledgements}

We thank all the participants in the study for their support. Our gratitude is extended to the pharmacists.

\section{References}

[1]. Darshana Bennadi, Self-medication: A current challenge, Journal of Basic and clinical Pharmacy, 5(1), 2014, 19-23.

[2]. Shuvashis Saha and Md.Tawhid Hossain, Evaluation of medicines dispensing pattern of private Pharmacies in Rajshahi, Bangladesh, BMC Health Services Research, 17(136), 2017, 1-8.

[3]. FDA's OTC Active Ingredients list 2010, Available From:

https://www.fda.gov/downloads/AboutFDA/CentersOffices/CDER/UCM135688.pdf. Accessed on: 24-03-2017.

[4]. Rajput MS, Mathur V, Yamini Satrawala, Veena Nair, Pharmacoepidemiological Study of Self-Medication in

[5]. Indore City, Indian journal of pharmacy practice, 3(1), Jan-Mar 2010, 25-30.

[6]. Kunal Chakraborty, Ananya Chakraborty, Sanayaima Devi and Jalina Devi, Family self medication in

[7]. Children attending a tertiary care hospital in northeast India, International journal of pharmaceutical sciences and research, 3(12), 2012, 4899-4902.

[8]. Joshi MC, Shalini, Sangeetha Agarwal, A questionnaire based study of self-medication practices among young population, Research Journal of Pharmaceutical, Biological and Chemical Sciences, 2(4), oct-dec 2011, 761-66.

[9]. KP Osemene and A Lamikanra, A Study of the Prevalence of Self-Medication Practice among University Students in Southwestern

[10]. Nigeria, Tropical Journal of Pharmaceutical Research, 11(4), August 2012, 683-689.

[11]. Supriya Gupta, Pawan Gupta, Prevalence of Self medication: A Review, Journal of Management Sciences and Technology 2(1), Oct 2014, 35-40

[12]. Ruiz ME, Risks of self-medication practices, Curr Drug Saf, 5(4), Oct 2010, 315-323 (Abstract).

[13]. Dr. Manoj Goyal, Dr. Monika Bansal, Dr. Majid farooq, Shinu Pottahil, Dr. Sanjay Bedi, Direct to Consumer Advertising: A Mixed Blessing, NJIRM, 6(3), May - June 2015, 113-117.

[14]. Luca Garofalo, Gabriella Di Giuseppe and Italo F. Angelillo, Self-Medication Practices among Parents in Italy, BioMed Research International, 2015, 1-8.

[15]. Shahbaz Baig, Self Medication Practices, Professional Med J, 19 (4), July-Aug 2012, 513-521.

[16]. N.A. El-Nimr, I.M.H. Wahdan, A.M.H. Wahdan and R.E. Kotb, Self-medication with drugs and complementary and alternative medicines in Alexandria, Egypt: prevalence, patterns and determinants, Eastern Mediterranean Health Journal, 21(4), 2015, 256-264.

[17]. M.G. Sangeetha Nair, T.P. Rajmohanan, and J. Kumaran, Self Medication Practices of Reproductive Age Group Women in Thiruvananthapuram District, South India: A Questionnaire - Based Study, Journal Of Pharmaceutical Sciences And Research, $5(11), 2013,220-225$.

[18]. Girma Belachew Gutema, Diriba Alemayehu Gadisa, Zerihun Abebe Kidanemariam, Derbew Fikadu Berhe et al, SelfMedication Practices among Health Sciences Students: The Case of Mekelle University, Journal of Applied Pharmaceutical Science 01 (10), 2011, 183-189.

[19]. A Auta, SB Banwat, CN Sariem, D Shalkur, B Nasara, and MO Atuluku, Medicines in pharmacy students' residence and selfmedication practices, J Young Pharm, 4(2), Apr-Jun 2012, 119-123.

[20]. Lucas R, Lunet N, Carvalho R, Langa J, Muanantatha M, Nkunda LP et al. Patterns in the use of medicines by university students in Maputo, Mozambique, Cad Saude Publica, 23, 2007, 2845-2852. [Pub Med]

[21]. Arzi A, Ashtarinezhad A, Sarahroodi S, Sawalha AF, Antibiotic self- medication among Southern Iranian University students, International Journal of Pharmacology, 6(1), 2010, 48-52.

[22]. Dr. Shumaila Humayun, Warda Imran, Iram Naheed, Nazish Javid, Misbah Hussain, Maheen Azhar, Analysis Of Self Medication Practices; A Descriptive Cross Sectional Study, The Professional Medical Journal, 23(5), 2016, 608-613.

[23]. Worku S, Mariam, A Practice of Self-medication in Jimma Town, Ethiop J Health Dev 17(2), 2003, $111-116$. 